\title{
A Genetical Study of the Feedback-sensitive Enzyme of Methionine Synthesis in Salmonella typhimurium
}

\author{
By K. F. CHATER* \\ Genetics Department, The University, Birmingham 15 \\ AND R. J. ROWBURY \\ Department of Botany and Microbiology, University College London, London W.C.I
}

(Accepted for publication 22 June 1970)

SUMMARY

The homoserine- $O$-transsuccinylase activity of three kinds of methionineexcreting mutants of Salmonella typhimurium was examined. In a metI mutant the enzyme was resistant to inhibition by methionine or its analogue $\alpha$-methylmethionine. Feedback inhibition in a met $J$ and a met $K$ strain was normal. met $I$ was dominant to $m e t I^{+}$only when coupled in the cis position with the wild-type allele of the closely-linked $m e t A$ (homoserine- $O$-transsuccinylase) gene, and a deletion analysis of nine metI mutations showed that they were all located within the met $A$ gene. Thus both the regulatory and catalytic sites of homoserine- $O$-transsuccinylase are specified by a single polypeptide species. An estimate was made of the length of the met $A$ gene, based on recombination data.

\section{INTRODUCTION}

The first step specific to methionine biosynthesis in Salmonella typhimurium and Escherichia coli is the $O$-succinylation of homoserine (Rowbury, 1964; Rowbury \& Woods, I964). Mutations in S. typhimurium resulting in the loss of homoserine- $O$ transsuccinylase activity are located in the met $A$ gene, which is cotransduced with a second methionine structural gene (metH) (Childs \& Smith, 1969) and with genes controlling the biosynthesis of purines ( $p u r D, H$ ) and thiamine (thi) (Sanderson, 1967). Sensitive regulation of methionine synthesis is achieved by the feedback inhibition of homoserine- $O$-transsuccinylase activity by methionine and its important derivative $S$-adenosylmethionine, either singly or (more effectively) in combination (Rowbury, 1964; Lee, Ravel \& Shive, 1966). False feedback inhibition by the methionine analogue $\alpha$-methylmethionine has been demonstrated, and since this substance is unable to replace methionine in protein synthesis, its addition to growing cultures rapidly inhibits further cell division (Schlesinger, 1967; Rowbury, I968; Smith, 1968).

Mutants of Salmonella typhimurium that were resistant to $\alpha$-methylmethionine and overproduced methionine were described by Lawrence, Smith \& Rowbury (1968). Genetical analysis of these mutants revealed two groups, one of which was defective in $m e t K$, a locus situated far from any of the known methionine genes in the linkage map, the other group being designated metI. metI mutations were all more than $95 \%$ cotransduced with met $A$, and it was considered probable that they possessed a homoserine- $O$-transsuccinylase that was not subject to inhibition by methionine or its

* Present address: John Innes Institute, Colney Lane, Norwich, NOR $70 F$. 
analogue. Preliminary deletion mapping experiments led Lawrence et al. (1968) to speculate that met $A$ and $m e t I$ might be separate cistrons, $m e t A$ specifying a catalytically active subunit of the enzyme and metI a regulatory subunit. This idea was reinforced by the data of Ayling \& Chater (1968), who found that three independent pairs of $m e t A$ and $I$ mutations had the same orientation relative to outside markers.

The present account includes biochemical evidence that metI mutations do indeed give rise to feedback inhibition resistance, and genetical evidence, from complementation and deletion mapping experiments, that they occur within the metA cistron. A preliminary account of some of the genetical experiments has appeared elsewhere (Chater, 1970b).

\section{METHODS}

Media. The media and most of the supplements used are given in an accompanying paper (Chater, 1970a). Additional supplements to minimal media were adenine $\mathrm{HCl}$ and L-tryptophan $(20 \mu \mathrm{g} . / \mathrm{ml}$.). Abbreviations used are: NA, nutrient agar; NB, nutrient broth; MA, minimal agar; MM, liquid minimal medium.

Organisms. The nomenclature is that of Sanderson (1967). Escherichia coli 1553/ KLF Io was provided by $\mathrm{K}$. Brooks Low, and is described in an accompanying paper (Chater, I970a). All other strains were derived from Salmonella typhimurium strain LT 2. Those previously described were: $m e t A 15, A 54, A 229$ and $A 309$, metA22tryB2, and metA43purEII (Smith \& Childs, 1966); argFIII, argFIIImetI708, metA746metI706, metB23metI708 and metB23metJ744 (Ayling \& Chater, I968); metI7or, I702, I703, I704, I705, I706, I708, and I7I2 (Lawrence et al. I968); argFIIIrec-30Ipyr (Chater, I970a), and metB23metK 747 (Chater, I969). Mutant metI749 was provided by P. D. Ayling, and strain metA7 was obtained by transduction of the double mutant metA7cysA2I (Smith \& Childs, 1966) to cysteine independence. The maintenance of stock cultures, and the propagation, assay and maintenance of transducing phage $P_{22}$, were as described by Smith (1961). Cultures were grown at $37^{\circ}$ unless otherwise stated. Growth experiments in MM were essentially as described by Lawrence et al. (1968).

Assay of homoserine-O-transsuccinylase activity. The incubation mixture and assay system for estimating the $\left[{ }^{14} \mathrm{C}\right]$ homoserine-dependent accumulation of $\left[{ }^{14} \mathrm{C}\right]-O$ succinylhomoserine by a cell suspension are described in the legend to Table $\mathrm{I}$.

Episome transfer and the detection of haploid segregants. The methods used are described in an accompanying paper (Chater, I970a).

Transduction. Transduction and recombinant analysis were as described by Ayling \& Chater (1968), except in the deletion analysis of metI mutants, when the normal method would have involved the use of too much expensive $\alpha$-methylmethionine. Instead, use was made of the methionine excretion of metI mutants, by analogy with a similar study of histidine feedback inhibition-resistant mutants of Salmonella typhimurium (Sheppard, 1964). Eighteen h. NB cultures of recipients were harvested by centrifugation and resuspended in culture volumes of $\mathrm{T} 2$ buffer (adsorption medium: Hershey \& Chase, 1952), and donor phage added at a multiplicity of infection of 5 . The transduction mixture was incubated at $37^{\circ}$ for $5 \mathrm{~min}$. before the addition of up to I ml. per tube to tubes containing $\mathrm{Io} \mathrm{ml}$. of molten minimal soft agar maintained at $45^{\circ}$. The contents of each tube were then poured into a Petri dish containing a thin solidified layer (IO ml.) of MA. Plates were incubated at $37^{\circ}$ for $48 \mathrm{~h}$., and at room temperature $\left(20\right.$ to $\left.25^{\circ}\right)$ for a further $24 \mathrm{~h}$. Upon examination with a binocular micro- 
scope at low magnification it was possible to distinguish methionine-excreting from non-excreting colonies: excretion resulted in growth of the background of methioninerequiring recipient cells, visible as a fuzzy edge to the excreting colony, while the boundaries of non-excreting colonies were smooth and clearly defined. Up to 300 colonies per plate could be scored. The reliability of the technique was established in reconstruction experiments with artificial mixtures of $m e t I$ and $I^{+}$strains in the presence of a large excess of a metA deletion mutant. In addition, as further confirmation of the scoring in all experiments, all apparently non-excreting colonies were restreaked on MA, and their resistance to $\alpha$-methylmethionine tested by replica plating. To

Table I. The effect of methionine and $\alpha$-methylmethionine on the synthesis of $O$-succinylhomoserine by strains met $B 23$ and metB23metI708

Organisms $\left(0.25 \mathrm{mg}\right.$. dry $\mathrm{wt} / \mathrm{ml}$.) were incubated at $37^{\circ}$ in a mixture consisting of glucose minimal medium (0.75 ml.), $\left.{ }^{[2} \mathrm{C}\right]$ homoserine (800 nmoles), and $\left[{ }^{14} \mathrm{C}\right]$ homoserine $(0.2 \mu \mathrm{Ci})$, with additions as stated in the table, and water to $1.5 \mathrm{ml}$. After $15 \mathrm{~min}$., tubes were heated in a boiling water-bath, and cell debris was removed by centrifugation. $\left[{ }^{14} \mathrm{C}\right]-O$-Succinylhomoserine in the supernatant fluids was estimated as follows: $0.5 \mathrm{ml}$. aliquots were treated with $0.1 \mathrm{ml}$. M-KOH, and heated on a water-bath at $100^{\circ}$ for I min. to convert $O$-succinylhomoserine to $N$-succinylhomoserine. Duplicate aliquots were left untreated. Treated and untreated samples were added to $5 \mathrm{~cm}$. columns of Dowex- 50 resin $\left(\mathrm{H}^{+}\right.$form), and eluted with water. $\mathrm{N}$-Succinylhomoserine passes through the column, while unreacted $\left[{ }^{14} \mathrm{C}\right]$ homoserine is retained. $3.5 \mathrm{ml}$. of each eluate was collected, of which $\mathrm{I} \mathrm{ml}$. was added to $\mathrm{I} 5 \mathrm{ml}$. of scintillation fluid (0.5\% butyl PBD in toluene-triton $X 100 ; 3: 2, \mathrm{v} / \mathrm{v}$ ) and counted for 5 min. in a Packard Tri-Carb Liquid Scintillation Spectrometer 3320. [ $\left.{ }^{14} \mathrm{C}\right]-O$-Succinylhomoserine was given by the difference between treated and untreated samples.

\begin{tabular}{|c|c|c|}
\hline \multirow[b]{2}{*}{ Additions } & \multicolumn{2}{|c|}{$\begin{array}{c}O \text {-Succinylhomoserine formed } \\
(\% \text { of control) }\end{array}$} \\
\hline & met $B 23$ & metB23metI708 \\
\hline None (control) & 100 & 100 \\
\hline \multicolumn{3}{|l|}{ L-Methionine } \\
\hline $0.02 \mathrm{~mm}$ & $3 \mathrm{I}$ & 108 \\
\hline $0.05 \mathrm{~mm}$ & 8 & 86 \\
\hline $0.25 \mathrm{~mm}$ & 0 & 92 \\
\hline \multicolumn{3}{|c|}{$\alpha$-Methyl-DL-methionine } \\
\hline $0.001 \mathrm{~mm}$ & 52 & 105 \\
\hline $0.005 \mathrm{~mm}$ & $5 \cdot 5$ & IOI \\
\hline $0.02 \mathrm{~mm}$ & 4 & 97 \\
\hline $0.05 \mathrm{~mm}$ & 3.5 & 90 \\
\hline $0.25 \mathrm{~mm}$ & 0 & 105 \\
\hline $\mathrm{I} \cdot \mathrm{O} \mathrm{mM}$ & 0 & 103 \\
\hline
\end{tabular}

confirm that any rare $m e t I^{+}$recombinants were not contaminants, any second auxotrophic marker present in the recipient was checked in the recombinants by replica plating. Where such markers were not available, the colonial morphology of the metI and $\mathrm{I}^{+}$recombinants was examined, as this quality was sufficient to distinguish between the different recipients used, and was therefore unlikely to be shared with any chance contaminant.

\section{RESULTS}

Tests of the sensitivity of methionine analogue-resistant mutants to feedback inhibition by methionine. The assay of homoserine- $O$-transsuccinylase depending on the homoserine-dependent accumulation of $\left[{ }^{14} \mathrm{C}\right]-O$-succinylhomoserine can be used only with 
$m e t B$ mutants, since the ester is further metabolized in other strains. The isolation of

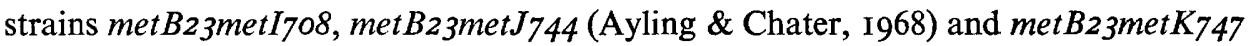
(Chater, 1969) permitted the study of feedback inhibition in representatives of three classes of methionine analogue-resistant mutants. The effects of added methionine and $\alpha$-methylmethionine on $O$-succinylhomoserine synthesis in the metI mutant and a $\mathrm{metI}^{+}$strain are given in Table I and Fig. I. External concentrations of methionine or $\alpha$-methylmethionine giving effectively total inhibition of $O$-succinylhomoserine synthesis in metI $^{+}$cells had no effect at all on this activity in the metI mutant. Since metB23metI708 cultures grew only in the presence of added methionine, one must assume that methionine could enter and be utilized by the cells, so that the only explanation for the observations in Table $I$ and Fig. I is that the homoserine- $O$ transsuccinylase of metB23metI708 was altered in such a way that it was no longer inhibited by methionine or $\alpha$-methylmethionine.

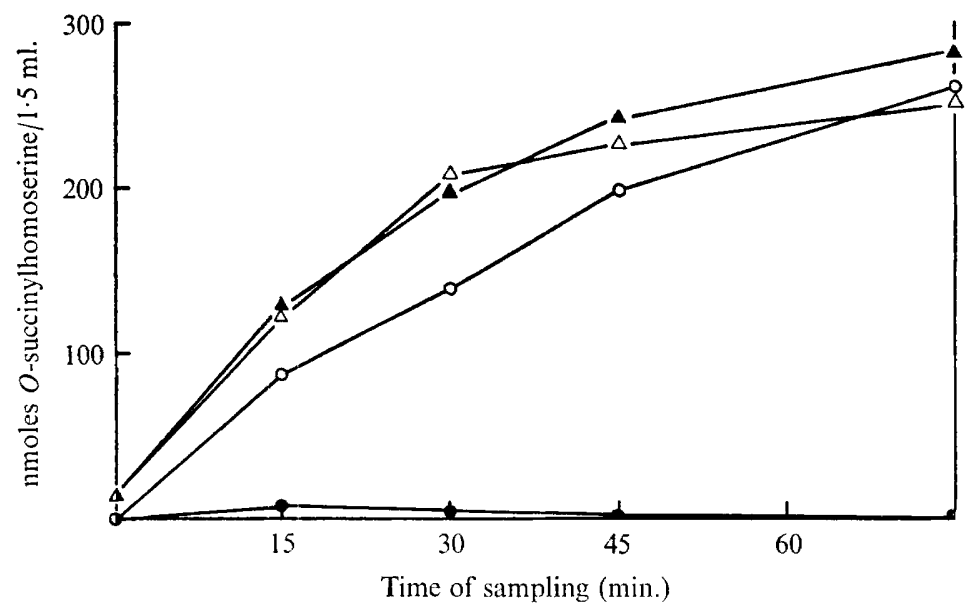

Fig. I. Time course for the synthesis of $O$-succinylhomoserine by strains metB23 and metB23met 1708 in the presence and absence of methionine. Organisms (0.25 $\mathrm{mg}$. dry wt $/ \mathrm{ml}$.) were incubated at $37^{\circ}$ in the incubation mixture described in the legend to Table $\mathrm{r}$. At the stated intervals, samples were removed and assayed for $\left[{ }^{14} \mathrm{C}\right]-O$-succinylhomoserine (see Table I). $O$, metB23 in absence of methionine; - met $B 23$ in presence of $0.1 \mathrm{~mm}$-methionine; $\triangle$, metB23metI708 in absence of methionine; $\Delta$, metB23metI708 in presence of $0.1 \mathrm{mM}-$ methionine.

The rate of $O$-succinylhomoserine synthesis in the met $J$ and met $K$ mutants was reduced in the presence of $\mathrm{L}$-methionine $(0.05 \mathrm{mM})$ to $7 \%$ and $5 \%$, respectively, of that obtained in controls lacking methionine. Thus neither met $J$ nor met $K$ mutations result in altered feedback sensitivity of homoserine- $O$-transsuccinylase.

Absence of complementation between metA and metI. Lawrence et al. (1968) suggested that met $A$ and $I$ might be separate genes. If they were, it should be possible to demonstrate complementation between them in a suitable strain. The genotype of the merodiploid required for such a test is met $A^{-} I^{-} \mid A^{+} I^{+}$. $\alpha$-Methylmethionineresistant growth of a strain of this genotype would indicate that the products of the $m e t A^{+}$and $I^{-}$alleles were complementing each other, i.e. met $A$ and $I$ were separate cistrons. The required merodiploid was obtained by transferring the episome KLF io (which carried the metA region of the Escherichia coli genome: Chater, 1970a), from 
its E. coli 1553 host, via Salmonella typhimurium argFIIIrec-30Ipyr, into strain met $A 746$ metI 706 , with selection on MA for prototrophic heterogenotes. In addition, for control purposes, KLF Io was transferred into strain $\arg F_{I I I}$ to give the merodiploid met $^{+} I^{+} / A^{+} I^{+}$, and into strain $\operatorname{argFIIImet} I_{708}$ to give the merodiploid $A^{+} I^{-} \mid A^{+} I^{+}$.

The growth of the heterogenotes and their haploid parents was followed in MM with and without the addition of $\alpha$-methylmethionine (Fig. 2). As expected, the haploid $A^{+} I^{+}$strain (Fig. $2 a$ ) was sensitive to the analogue. The presence of KLF IO in this strain $\left(A^{+} I^{+} / A^{+} I^{+}\right.$; Fig. $\left.2 d\right)$ increased its resistance a little (probably due to a

(a)

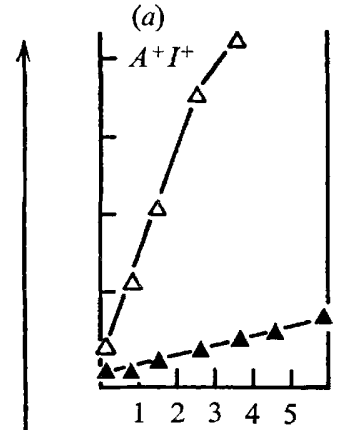

$\begin{array}{lllll}1 & 2 & 3 & 4 & 5\end{array}$ (b)
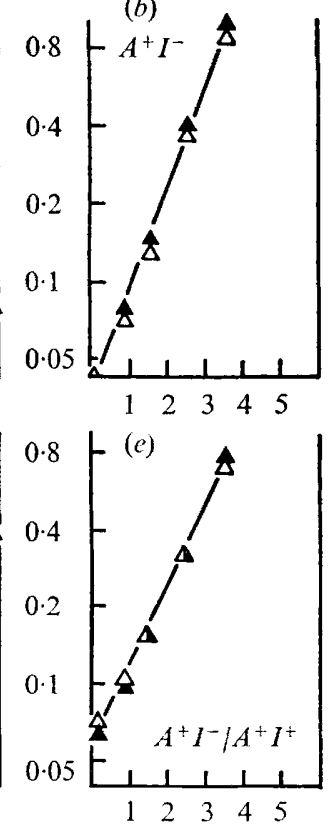

(c)
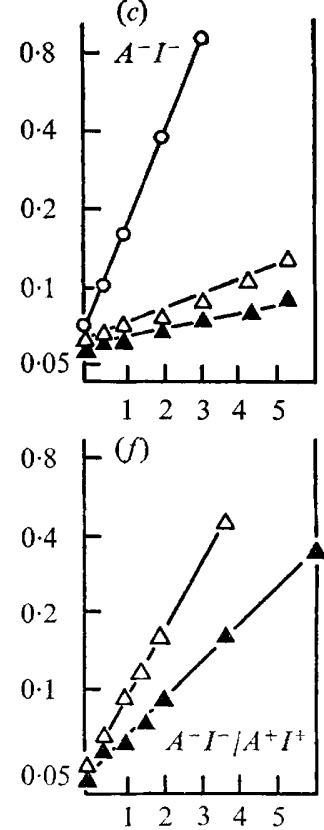

Hours

Fig. 2. A test of complementation between met $A$ and metI. The Escherichia coli episome KLF Io $\left(a r g F^{+}\right.$met $^{+}$met $\left.I^{+}\right)$was transferred into various Salmonella typhimurium strains and the growth of the haploid parent strains and their heterogenote derivatives was followed, by extinction measurements, in minimal medium containing: $\triangle$, no addition; $\boldsymbol{\Delta}$, DL$\alpha$-methylmethionine (1000 $\mu \mathrm{g} . / \mathrm{ml}$.); $\mathrm{O}$, L-methionine $(20 \mu \mathrm{g} . / \mathrm{ml}$.). The relevant genotypes (i.e. with respect to met $A$ and $I$ ) are indicated on the graphs: where merodiploids were used, relevant episomal markers are given after a diagonal stroke.

met $A$ gene dosage effect), though not to a level comparable with that of the $A^{+} I^{-}$ strain (Fig. $2 b$ ), which, moreover, was unaffected by possession of the episome $\left(A^{+} I^{-}\right.$ $A^{+} I^{+}$; Fig. 2e). Thus metI was dominant to $m e t I^{+}$(as had been anticipated in the design of the complementation test). Figure $2 f$ shows that the presence of the episome in the $A^{-} I^{-}$double mutant (giving the critical genotype $A^{-} I^{-} / A^{+} I^{+}$) permitted its growth in unsupplemented MM, while the haploid strain (Fig. $2 c$ ) gave only slow, leaky growth in MM unless methionine was added. However, the growth of the $A^{-} I^{-} \mid A^{+} I^{+}$strain was inhibited by $\alpha$-methylmethionine to about the same extent as 
was that of the $A^{+} I^{+} / A^{+} I^{+}$strain (Fig. $2 d$ ). Thus the dominance of metI- to metI $I^{+}$ suggested by Fig. $2 e$ was apparently dependent upon its coupling in the cis position with $m e t A^{+}$. It was therefore concluded that the met $A$ and $I$ mutations used in the complementation test were probably located in the same cistron.

This conclusion is based on the assumption that the Escherichia coli and Salmonella typhimurium homoserine- $O$-transsuccinylases have not undergone enough changes during evolution from a presumed common ancestral form to prevent the efficient formation of mixed enzyme in hybrids. Two lines of evidence suggest that this assumption is justified. First, $E$. coli-S. typhimurium hybrid tryptophan biosynthetic enzyme complexes are easily obtained when extracts of the two organisms are mixed (Balbinder, I964; Ito, I969); and secondly, the expression of the histidine and methionine structural genes of $S$. typhimurium is efficiently controlled by regulatory elements derived from E. coli (Fink \& Roth, 1968; Chater, 1970a). It seems that those sites of homologous enzymes from the two organisms that are concerned with quaternary interactions have undergone relatively little evolutionary divergence, so that the absence of complementation observed between met $A$ and $I$ is unlikely to be due to failure of the required quaternary interactions to take place.

Deletion mapping of metI mutations. The absence of complementation between metA746 and metI706 described above cast doubt on the suggestion of Lawrence et al. (I968) that met $A$ and $I$ were separate genes. To clarify the relationship between mutations causing metA and metI phenotypes, the locations of metI mutations in the met $A$ deletion map were investigated. The original deletion map of Smith \& Childs (I966) has been modified by the properties of a new deletion mutant, met A596, which gave prototrophic recombinants with metA43 but not with metAI5 (D. A. Smith, personal communication). The resulting improvement in the map (Fig. 3) received support from the occurrence of prototrophic recombinants in the crosses met $A 43 \times A 54$ or $A 746$, and their absence in the crosses metAI5 $\times A 54$ or $A 746$ (Chater, 1969). The criterion established by Smith \& Childs (I966) for absence of recombination between two met $A$ mutations was failure to produce prototrophic recombinants in three replicate reciprocal transduction crosses. Their crosses were performed by a spot technique in which crosses between non-allelic methionine mutants gave 40 to 100 recombinant colonies per spot. In order that the resolution of the mapping of metI mutations should be comparable with that obtained by Smith \& Childs, at least 500 recombinant colonies were examined before absence of recombination between the donor and recipient mutant sites was concluded.

The results of crosses involving 9 metI mutants are presented in Table 2. Mutant I702 gave no $I^{+}$colonies among 506 recombinants obtained from a cross with metA229, a mutation located at one extremity of the deletion map (Smith \& Childs, 1966). A229 and 1702 were therefore placed in the same deletion group (x in Fig. 3). In only one case, in which $I 705$ was the donor, was an $I^{+}$recombinant obtained in crosses with metA7, but so few prototrophic recombinants occurred with this recipient that no significance could be attached to the negative results, which are therefore not included in Table 2. The positive result with $I 705$ is, however, taken into account in the assignment of this mutation to deletion group x. The result for I706 did not agree with that given by Lawrence (1967), who obtained one met $^{+}$colony among 90 recombinants from an $A 43 \times I 706$ cross. No explanation can be offered for this disparity. 


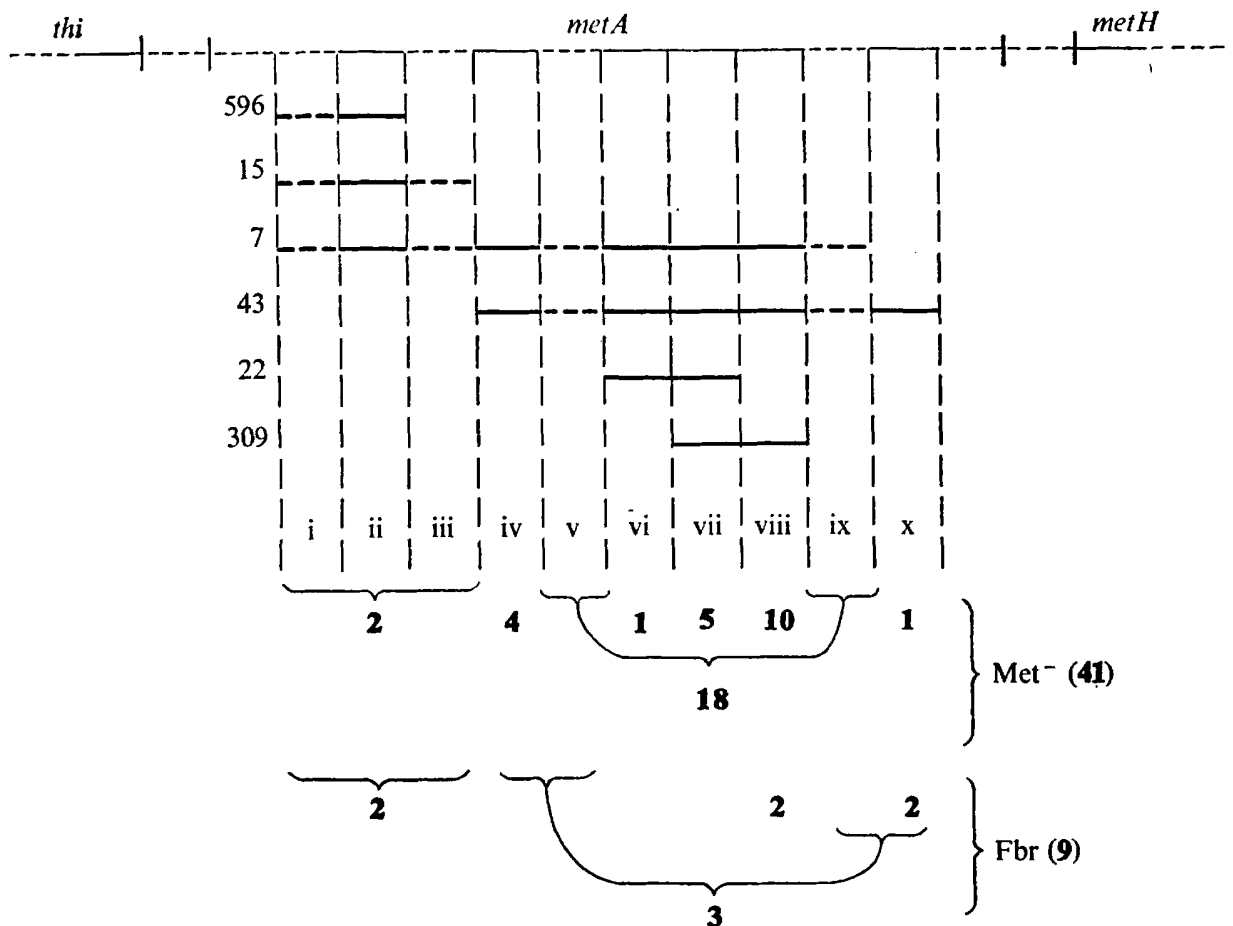

Fig. 3. A revised deletion map of the met $A$ gene. The map is based on that of Smith \& Childs (1966, and unpublished) and on data given in Results. Heavy unbroken lines represent regions deleted in met $A$ deletion mutants (isolation numbers given at left end of each line). Heavy broken lines indicate regions whose existence is not certain. Deletion regions are not drawn to scale. Bold-face figures give the numbers of methionine auxotrophic $\left(\mathrm{Met}^{-}\right)$and feedback resistance ( $\mathrm{Fbr}$ ) mutations so far mapped in the various deletion regions ( $\mathrm{i}$ to $\mathrm{x}$ ). The total numbers mapped are also given (far right). The orientation of regions vi, vii and viii relative to the rest of the map has not been established.

\section{Table 2. Deletion mapping of metI mutations}

Phage P22 propagated on metI mutants was used to transduce met $A$ deletion mutants to prototrophy. Recombinants were scored for inheritance of the metI phenotype (see Methods). In the table, the number of colonies with met $^{+}$phenotype is followed in each case by the total number of colonies scored. Assignment to deletion groups refers to Fig. 3, and for metI 702 and 705 utilizes additional information given in the Results. Parentheses indicate assignments based on negative results with fewer than 500 recombinant colonies.

No. of colonies with metI $^{+}$phenotype among recombinants

from cross with recipient

Donor
metI I70r
metI I02
metI I03
metI I04
metI $I_{705}$
metI 706
metI 708
metI712
met I 749

\begin{tabular}{lcccc}
\hline metA43 & metAr5 & metA596 & metA22 & metA309 \\
$4 / 724$ & $0 / 578$ & $1 / 372$ & n.t. & n.t. \\
o/1162 & I/103 & n.t. & n.t. & n.t. \\
I3/1775 & $0 / 660$ & $2 / 886$ & n.t. & n.t. \\
$0 / 894$ & $4 / 150$ & $3 / 67$ & $1 / 56$ & $0 / 181$ \\
$0 / 1934$ & $0 / 287$ & $3 / 217$ & $14 / 82$ & $11 / 577$ \\
$0 / 1830$ & $4 / 439$ & $1 / 144$ & $9 / 45$ & $23 / 648$ \\
o/737 & $0 / 193$ & $2 / 126$ & $11 / 48$ & $9 / 162$ \\
o/660 & $0 / 236$ & $2 / 243$ & $10 / 69$ & $26 / 579$ \\
o/526 & $9 / 318$ & $5 / 200$ & $2 / 149$ & $0 / 1065$
\end{tabular}

Deletion group i or iii $\mathrm{x}$ i or iii (viii) $\mathbf{x}$ iv, $v$, ix or $x$ iv, $v$, ix or $x$ iv, $v$, ix or $x$ n.t. $=$ Not tested. viii 
These results confirmed the conclusion drawn from the metA-I complementation test, namely that mutations leading to the met $A$ and $I$ phenotypes are located in the same gene. Moreover, mutations resulting in the metI phenotype did not seem to be clustered in any particular region(s) of the met $A$ gene.

The frequency of recombination within the met $A$ gene. Using met $A$ and $I$ mutations situated at the ends of the deletion map ( $A 54, I 70 I$ and $I_{703}$ in deletion groups i, ii or iii, and $A 229$ and $I 702$ in deletion group x; see Results, preceding section, and Fig. 3), crosses were made to estimate the frequency of recombination along the met $A$ gene (more precisely, that part of met $A$ containing deletion regions iv to ix, within which $86 \%$ of all met $A$ and $I$ point mutations tested have been located: Fig. 3) during $\mathrm{P} 22$-mediated transduction (Table 3 ). In crosses I \& 3 the generation of $m e t A^{+}$recombinants required

\section{Table 3. Estimation of recombination frequency within the metA gene during transduction}

Phage P22 propagated on metI mutants was used to transduce met $A$ auxotrophs to prototrophy. Recombinants were scored for inheritance of metI phenotype by replica plating to $\mathrm{MA}+\alpha$-methylmethionine. Controls indicated that $\mathrm{met}^{+}$colonies were unlikely to have resulted from recipient reversion.

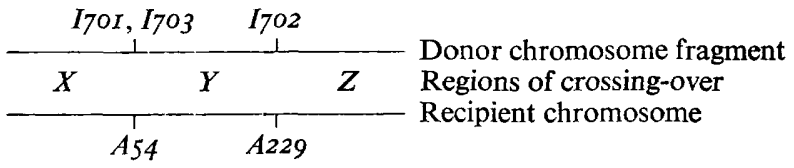

\begin{tabular}{|c|c|c|c|c|c|}
\hline \multirow{3}{*}{ 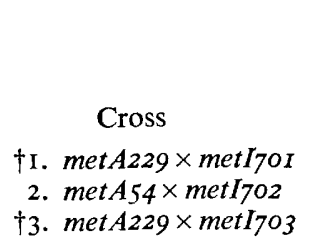 } & \multicolumn{3}{|c|}{$\begin{array}{l}\text { No. of recombinants with } \\
\text { crossing-over in regions }\end{array}$} & \multirow{2}{*}{\multicolumn{2}{|c|}{$\begin{array}{c}\text { Estimated } \\
\text { recombination } \\
\text { frequency in region } Y^{*}\end{array}$}} \\
\hline & $X, Y$ & $Y, Z$ & $X, Z$ & & \\
\hline & $18\left(I^{+}\right)$ & $\frac{\text { I } 3\left(I^{+}\right)}{29\left(I^{+}\right)}$ & $\begin{array}{l}708\left(I^{-}\right) \\
508\left(I^{-}\right) \\
567\left(I^{-}\right)\end{array}$ & $\left\{\begin{array}{l}0.026 \\
0.040\end{array}\right.$ & mean 0.033 \\
\hline * Calculated as follows: & $\frac{(X, Y)+}{(X, Y)+(}$ & $\frac{Z)}{Z)+[]^{\prime}}$ & & & \\
\hline
\end{tabular}

where $(X, Y)$ and $(Y, Z)$ are the frequencies of $X, Y$ and $Y, Z$ recombinants per $X, Z$ recombinant (represented by the figure ' $I$ ' in the denominator) obtained from crosses with reciprocal marker arrangements. The denominator is doubled to take account of the requirement for two recombination events in the generation of a viable recombinant. Mutations metA54, I $70 I$ and $I_{703}$ on the one hand, and $A 229$ and I7O2 on the other, are taken to define the ends of region $Y$ of the diagram.

$\uparrow$ Data of P. D. Ayling.

a recombination event to the right, and in cross 2 to the left, of the met $A$ gene. Combining the data from crosses $I$ and 2 or crosses 2 and 3, estimates of the recombination frequency along the met $A$ gene could therefore be made that took into account differences between the numbers of recombination events occurring on either side of the gene. The mean of the two estimates obtained was 0.033 , i.e. I in 30 of all the recombination events occurring along the whole transduction fragment took place within the met $A$ gene. 


\section{DISCUSSION}

The failure of methionine or $\alpha$-methylmethionine to inhibit $O$-succinylhomoserine synthesis in a metI mutant (Table I ; Fig. I) was attributable either to failure of these substances to penetrate the cells, or to an alteration of homoserine- $O$-transsuccinylase such that it was not sensitive to feedback inhibition. Two observations precluded the former interpretation. First, strain metB23metI 708 grew at the same rate as strain met $B 23$ on methionine at concentrations down to $0.02 \mathrm{mM}$ (i.e. the lowest concentration used in these experiments: R. J. Rowbury, unpublished observations); and secondly, $\alpha$-methylmethionine resistance was dominant to sensitivity in a metI $^{-} /$met $^{+}$ heterogenote (Fig. 2e), which contrasts with the observation of Ames \& Roth (I968) that histidine analogue resistance resulting from mutation of the histidine permease gene was recessive to sensitivity. Thus the metI gene product cannot be a component of the methionine transport system, so must be a component of homoserine- $O$-transsuccinylase. This conclusion has also recently been reached by D. A. Lawrence (personal communication), who has tested the feedback sensitivity of homoserine- $O$ transsuccinylase activity in cell-free extracts of four other metI mutants: in no case was the activity affected by methionine or $\alpha$-methylmethionine.

Smith \& Childs (I966) observed no abortive transduction, indicating no complementation, between strains bearing any of 37 met $A$ point mutations, all of which were located within the met $A$ deletion map; hence the map involves a single cistron only. As metI mutations were scattered within this map, and one of them failed to show complementation with a metA mutation, met $A$ and $I$ mutations must both result in alterations of the same polypeptide, which must specify both the substrate and the inhibitor binding sites of homoserine- $O$-transsuccinylase. Thus aspartate transcarbamylase in Escherichia coli remains the only case yet described in which the catalytic and regulatory sites of an enzyme are carried by distinct polypeptide species (Gerhart \& Schachman, 1965). Deletion mapping of histidine feedback-resistant mutants of the hisG gene of Salmonella typhimurium (Sheppard, I964) gave similar results to those described in the present work, though the clustering of most of the $h i s G$ feedback resistance mutations in a single region of the his $G$ deletion map is in contrast to the lack of gross clustering of methionine feedback resistance mutations in the metA map (Fig. 3). As metI mutations are now known to be situated within the $m e t A$ gene, such mutations will in future publications be designated met $A$ (e.g. metI7or will become metA7or). This accords with the convention suggested by Demerec, Adelberg, Clark \& Hartman (1966).

Finally, by combining the results of the deletion mapping with those of three-point transduction crosses described by Ayling \& Chater (1968) (which placed metI706 between met $A 746$ and met $H$, and $A I_{5}$ between $I 749$ and $t h i$ ), the met $A$ deletion map can be orientated unambiguously with respect to met $H$ and thi. This orientation is indicated in Fig. 3. The estimated recombination frequency of 0.033 along the major part of the met $A$ gene, i.e. that containing deletion regions iv to ix (Fig. 3), indicates that it occupies about $1 / 30$ th part of the average transduction fragment carrying it (assuming that recombination events occurred at random in the crosses analysed in Table 3).

We are grateful to Dr D. A. Smith, Dr D. A. Lawrence and Dr P. D. Ayling for communicating their unpublished results to us, and to $\mathrm{Mr} \mathrm{R}$. J. Harold for useful 
discussion. Part of this work was carried out by one of us (K.F.C.) during tenure of a Science Research Council Research Studentship, and formed part of a Ph.D. thesis (Chater, 1969) submitted to the University of Birmingham.

\section{REFERENCES}

Ames, G. F. \& Roth, J. R. (1968). Histidine and aromatic permeases of Salmonella typhimurium. Journal of Bacteriology 96, I742-1749.

Ayling, P. D. \& ChATER, K. F. (I968). The sequence of four structural and two regulatory methionine genes in the Salmonella typhimurium linkage map. Genetical Research 12, 34I-354.

BALBINDER, E. (1964). Intergenic complementation between A and B components of bacterial tryptophan synthetases. Biochemical and Biophysical Research Communications 17, 770-774.

CHATER, K. F. (1969). Linkage and Dominance Studies of Genes Controlling Methionine Synthesis in Salmonella typhimurium. Ph.D. Thesis, Birmingham University.

Chater, K.F. (1970a). Dominance of the wild-type alleles of methionine regulatory genes in Salmonella typhimurium. Journal of General Microbiology 63, 95-109.

ChATER, K. F. (1970 $b$ ). A genetical study of feedback inhibition of methionine synthesis in Salmonella typhimurium. Heredity 25, 154.

Childs, J. D. \& SмrTH, D. A. (1969). New methionine structural gene in Salmonella typhimurium. Journal of Bacteriology 100, 377-382.

Demerec, M., Adelberg, E. A., Clark, A. J. \& Hartman, P. E. (1966). A proposal for a uniform nomenclature in bacterial genetics. Genetics, Princeton 54, 6I-76.

Fink, G. R. \& Roth, J. R. (1968). Histidine regulatory mutants in Salmonella typhimurium. VI. Dominance studies. Journal of Molecular Biology 33, 547-557.

Gerhart, J. C. \& Schachman, H. K. (I965). Distinct subunits for the regulation and catalytic activity of aspartate transcarbamylase. Biochemistry 4, 1054-1062.

Hershey, A. D. \& Chase, M. (1952). Independent function of viral protein and nucleic acid in the growth of bacteriophage. Journal of General Physiology 36, 39-5I.

Iтo, J. (I969). Hybrid anthranilate synthetase molecules from Enterobacterial sources. Nature, London 223, 57-59.

LaWrence, D. A. (I967). Methionine Analogue-resistant Mutants of Salmonella typhimurium. Ph.D. Thesis, Birmingham University.

LAWRENCE, D. A., SMith, D. A. \& Rowbury, R. J. (1968). Regulation of methionine synthesis in Salmonella typhimurium: mutants resistant to inhibition by analogues of methionine. Genetics, Princeton 58, 473-492.

LeE, L. W., RAVEL, J. M. \& ShIVE, W. (I966). Multimetabolite control of a biosynthetic pathway by sequential metabolites. Journal of Biological Chemistry 24I, 5479-5480.

RowbURY, R. J. (1964). Synthesis of cystathionine and its control in Salmonella typhimurium. Nature, London 203, 977-978.

RowbURY, R. J. (1968). The inhibitory action of $\alpha$-methylmethionine on Escherichia coli. Journal of General Microbiology 52, 223-230.

Rowbury, R. J. \& Woods, D. D. (1964). $O$-Succinylhomoserine as an intermediate in the synthesis of cystathionine by Escherichia coli. Journal of General Microbiology 36, 34I-358.

SANDERSON, K. E. (1967). Revised linkage map of Salmonella typhimurium. Bacteriological Reviews 3I, 354-372.

SCHLESINGER, S. (1967). Inhibition of growth of Escherichia coli and of homoserine-O-transsuccinylase by $\alpha$-methylmethionine. Journal of Bacteriology 94, 327-332.

ShePpARD, D. E. (1964). Mutants of Salmonella typhimurium resistant to feedback inhibition by L-histidine. Genetics, Princeton 5o, 6 I I-623.

SMITH, D. A. (I96I). Some aspects of the genetics of methionineless mutants of Salmonella typhimurium. Journal of General Microbiology 24, 335-353.

Sмrtн, D. A. \& ChiLds, J. D. (1966). Methionine genes and enzymes of Salmonella typhimurium. Heredity 21, 265-286.

SMITH, R. C. (1968). Growth and nucleic acid synthesis of Salmonella typhimurium inhibited by $\alpha$-methylmethionine. Canadian Journal of Microbiology 14, 331-335. 